\title{
Pengenalan Safety Injury Untuk Anak Sekolah Dasar
}

\author{
Maria Putri Sari Utami \\ Prodi Diploma 3 Keperawatan, Sekolah Tinggi Ilmu Kesehatan Notokusumo Yogyakarta \\ Email : mariaputrisari88@gmail.com
}

\begin{abstract}
Abstrak
Cidera/luka ringan sering terjadi di masyarakat terutama di usia anak-anak. Penanganan luka ringan di masyarakat belum sesuai dengan teori yang ada. Pendekatan melalui peningkatan pengetahuan diharapkan dapat mengubah cara penanganan luka ringan sehingga dapat terhindar dari infeksi. Metode yang digunakan adalah penyuluhan yang meliputi ceramah, diskusi, dan survey terkait pengetahuan tentang perawatan luka ringan sehari-hari. Media yang digunakan adalah video audiovisual animasi. Kegiatan ini berlangsung di SD N Pandak, Terban, Bantul. Peserta penyuluhan sebanyak 35 siswa yang terdiri dari kelas IV sampai kelas VI. Hasil survey menunjukkan tingkat pengetahuan tentang perawatan luka ringan sehari-hari $68 \%$ baik, 29\% cukup, dan 3\% kurang baik. Dalam hal ini menandakan setelah dilakukan penyuluhan siswa sekolah dasar memiliki pengetahuan yang baik. Edukasi, pendampingan, dan pelatihan kader kesehatan disekolah terkait perawatan luka ringan sehari-hari perlu terus dilakukan secara intensif dalam rangka mencapai derajat kesehatan anak usia sekolah dan memperbaiki kebiasaan masyarakat yang salah.
\end{abstract}

Kata Kunci : anak, cidera, luka ringan

\begin{abstract}
Injuries/mild wounds often occur in the community especially in the age of children. The handling of minor injuries in society has not been in accordance with existing theories. The approach through increased knowledge is expected to change the way the handling of mild wounds can avoid infection. The methods used are counseling that include lectures, discussions, and surveys regarding the knowledge of daily mild wound care. The Media used is an animated audiovisual video. This activity took place at SD N Pandak, Terban, Bantul. The counseling participants were 35 students consisting of class IV until class VI. Results of the survey showed a level of knowledge about daily mild wound care $68 \%$ good, $29 \%$ enough, and $3 \%$ less good. In this case signifying after the counseling of elementary school students have a good knowledge. Education, mentoring, and training of health cadres in the treatment of daily mild wound care need to continue to be done intensively in order to reach the health degree of school-age children and improve the habit of the wrong society.
\end{abstract}

Keywords: children, injuries, minor injuries

http://ejournal.urindo.ac.id/index.php/PAMAS

Article History :

Submitted 19 Maret 2020, Accepted 30 Oktober 2020, Published 31Oktober 2020 


\section{PENDAHULUAN}

Cedera pada anak yang tidak disengaja dianggap sebagai masalah kesehatan masyarakat terkemuka karena menjadi salah satu penyebab yang dapat dicegah dari mortalitas anak dan morbiditas. Di Uni Eropa diperkirakan bahwa setiap hari sekitar 30,000 anak dirawat di IGD karena cedera [1,2]. Di sisi lain, menurut beberapa penelitian sebagian besar cedera anak dapat dicegah.

Cedera dapat bersifat ringan hingga berat. Cedera ringan dapat ditangani dengan cepat di rumah, sedangkan cedera berat, setelah mendapat pertolongan pertama di rumah, harus dibawa ke pelayanan kesehatan untuk mendapatkan pertolongan lanjutan. Dampak cedera dapat bersifat ringan hingga fatal, sebagai contoh yaitu tergoresnya bagian tubuh oleh benda tajam dapat berdampak ringan, seperti luka terbuka ukuran kecil. Namun, bila luka tidak segera dibersihkan dan ditutup, dapat menjadi infeksi hingga kematian [3]. Cedera akan sembuh tanpa komplikasi apabila segera mendapatkan penanganan yang tepat, namun apabila tidak tertangani dengan baik akan menimbulkan kecacatan hingga kematian [4]. Secara global, cedera adalah penyebab kematian paling umum urutan ketiga pada anak-anak dan merupakan masalah utama. Lebih dari 660.000 anak usia 0-14 tahun meninggal akibat cedera pada tahun 2012. Cedera yang tidak disengaja (lalu lintas jalan, tenggelam, luka bakar, jatuh dan racun) menyebabkan sebagian besar kematian ini. Negara-negara berpenghasilan rendah dan menengah bertanggung jawab atas $90 \%$ dari semua kematian cedera yang tidak disengaja (5-44 tahun) [5].

Berdasarkan hasil studi pendahuluan didapatkan data melalui hasil wawancara kepala sekolah dan 10 murid SD N Terban, Pandak, bantul diketahui bahwa siswa tidak pernah diajarkan tentang prosedur penanganan luka ringan karena tidak adanya tenaga terlatih yang mengajarkan topik tersebut dan 5 dari 10 orang siswa mengatakan apabila mengalami luka yang mereka lakukan membiarkan luka terbuka hingga sembuh, 2 orang mengatakan menutupnya dengan plester, 3 orang mengatakan apabila luka, tindakan yang dilakukan adalah membilas dengan air saja. Responden mengatakan luka yang sering dialami adalah luka lecet akibat terjatuh ketika bermain, luka iris karena benda tajam, dan luka bakar (terkena knalpot ataupun air panas). 
Salah satu cara untuk melakukan pertolongan pertama cedera pada anak adalah dengan pendidikan kesehatan. Promosi kesehatan adalah segala bentuk kombinasi pendidikan kesehatan dan intervensi yang dirancang untuk memudahkan perubahan perilaku dan lingkungan yang kondusif bagi kesehatan [6]. Pendidikan kesehatan yang dapat diterapkan salah satunya adalah dengan metode video edukasi.

\section{METODE}

Program dilakukan dengan metode penyuluhan dengan menggunakan video edukasi yang mudah diterima oleh siswa sekolah dasar. Pelaksanaan program ini dilakukan dengan melibatkan guru SD N Terban, Pandak, Bantul dan murid kelas IV, V, dan VI dengan jumlah total 35 siswa. Kegiatan ini berlangsung pada bulan Februari 2020. Kegiatan yang dilakukan berupa penyuluhan kesehatan dengan tahapan sebagai berikut :

\section{Tahap 1 :}

Tahap 1 adalah tahap apersepsi mengenai materi yang akan diberikan.

\section{Tahap 2}

Tahap 2 adalah tahap Penyampaian materi. Materi disampaikan pada siswa secara komunikatif dan interaktif agar dapat dengan mudah dipahami. Media yang digunakan adalah video edukasi animasi dan lagu yang memiliki pesan edukasi. Penyampaian materi ini ditutup dengan diskusi dan tanya jawab dengan siswa.

\section{Tahap 3}

Tahap 3 adalah pengukuran pengetahuan melalui kuesioner dengan post-test. Kuesioner disusun untuk mendalami tingkat pengetahuan anak SD setelah dilaksanakann penyampaian materi dan diskusi. Kuesioner terdiri dari 8 pertanyaan tertutup (pilihan benar dan salah) terkait dengan penanganan luka ringan sehari-hari.

Data hasil isian kuesioner kemudian diolah dengan analisa deskriptif berdasarkan kelompok variabel.

\section{HASIL DAN PEMBAHASAN}

Suasana kegiatan antara tim penyuluh dan siswa tersaji pada gambar 1. 


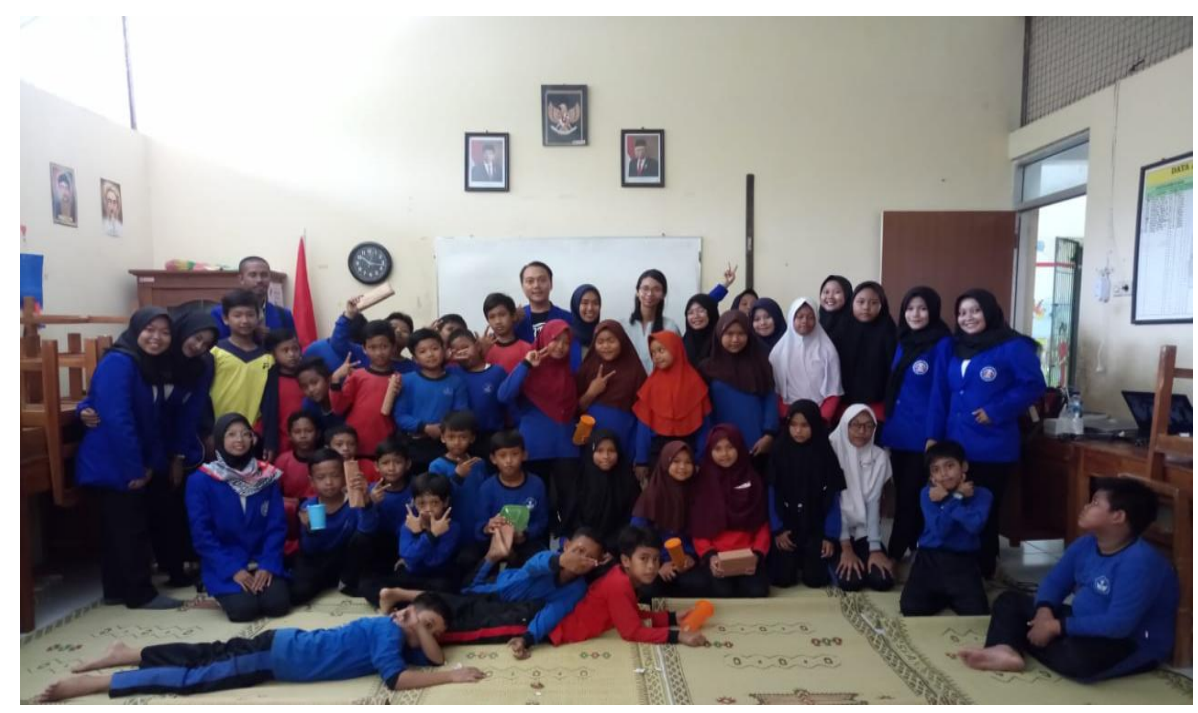

Gambar 1. Foto kegiatan setelah penyuluhan selesai dilaksanakan

Distribusi karakteristik peserta tersaji pada gambar 2 dan 3. Diketahui jenis kelamin sebanyak 69\% adalah laki-laki dan $31 \%$ perempuan. Untuk tingkat pendidikan diketahui $31 \%$ kelas IV, $31 \%$ kelas V, dan $38 \%$ kelas VI.

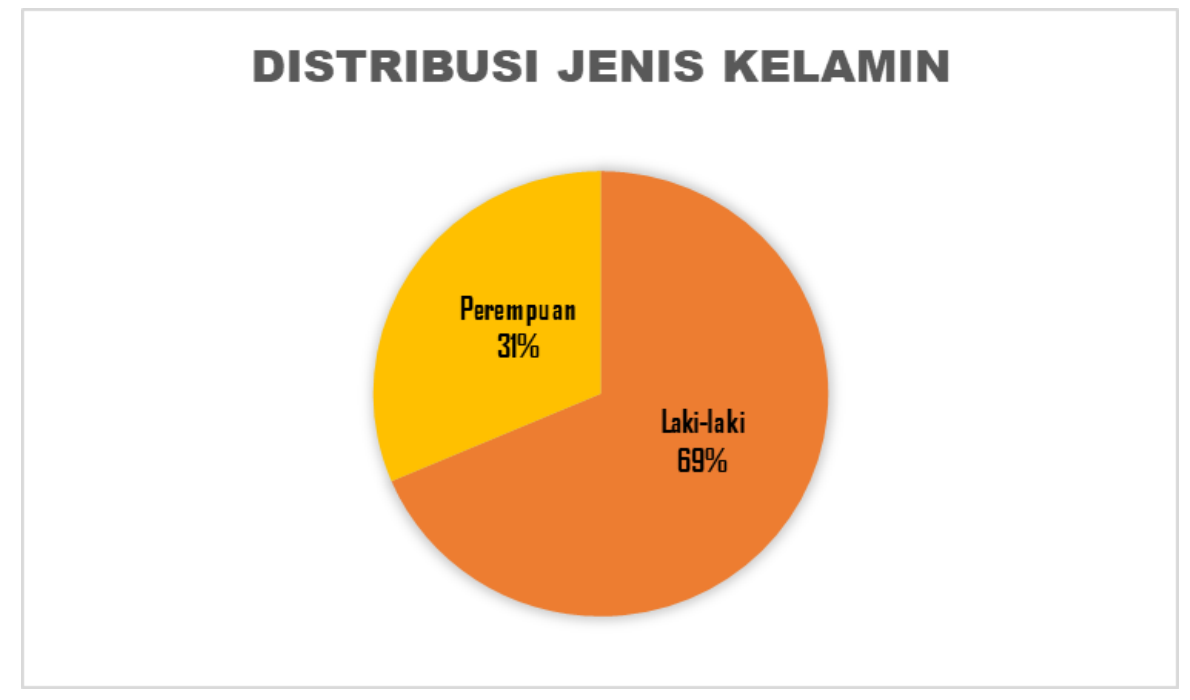

Gambar 2. Distribusi frekuensi jenis kelamin 


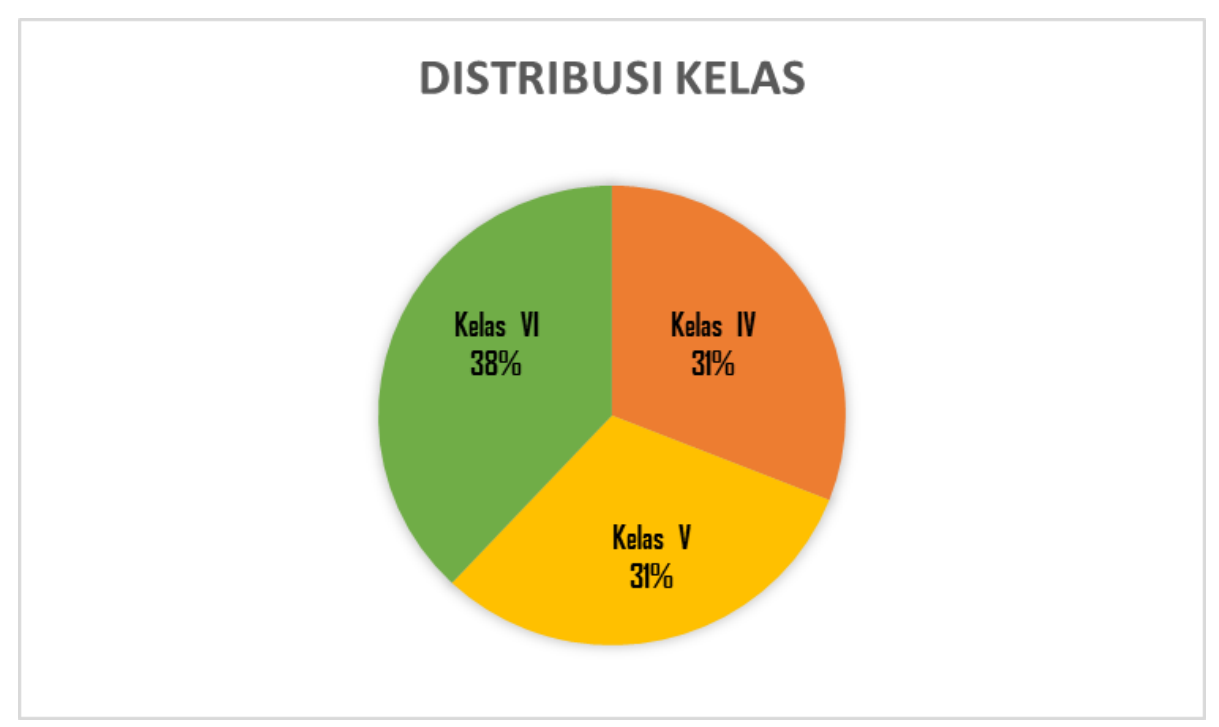

Gambar 3. Distribusi frekuensi kelas

Setelah kegiatan ini berlangsung, pengetahuan siswa tentang penanganan luka ringan sehari-hari diukur menggunakan kuesioner. Diketahui bahwa 68\% siswa yang memiliki pengetahuan baik, dan hanya 3\% siswa yang memiliki pengetahuan kurang.

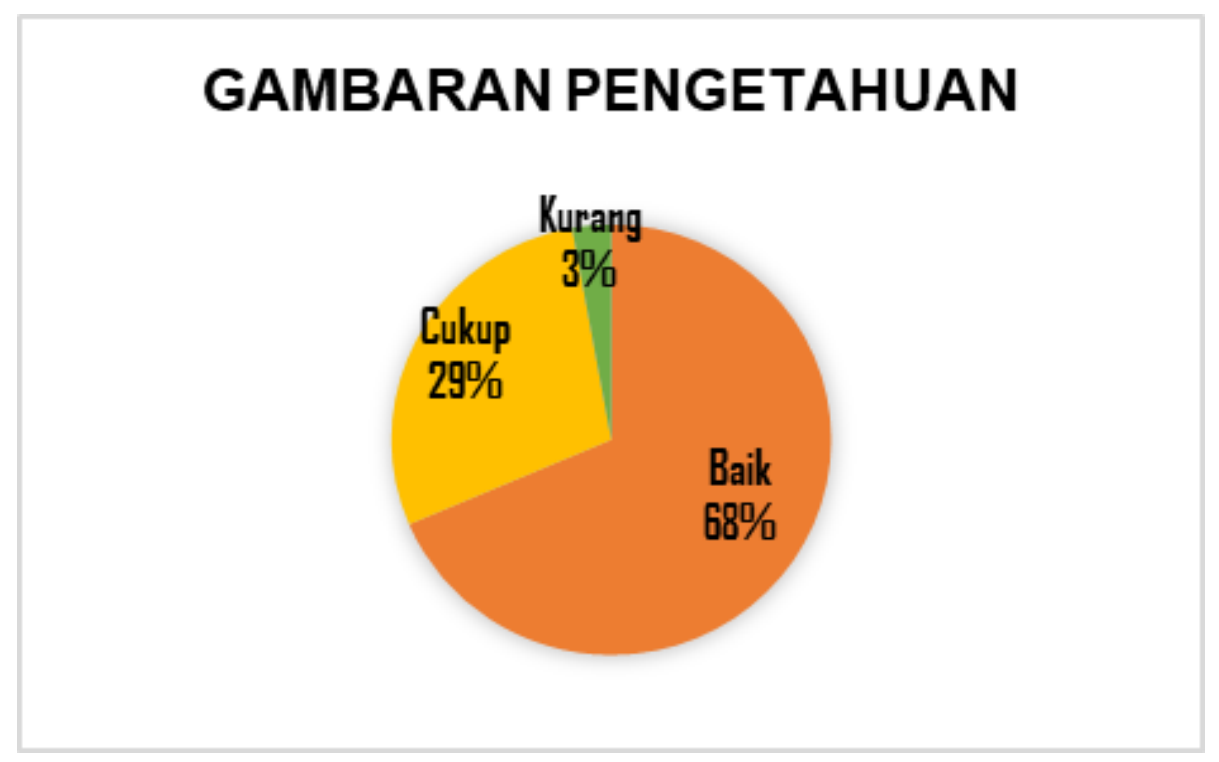

Gambar 4. Tingkat pengetahuan siswa setelah kegiatan 
Pengetahuan (knowledge) adalah hasi Itahu dari manusia, yang sekadar menjawab pertanyaan "what" misalnya apa air, apa manusia, apa alam dan sebagainya [7].

Media audio visual sesuai untuk anak usia sekolah, karena dapat mengembangkan imajinasi dan aktivitas belajar anak dalam suasana menyenangkan sehingga dapat merangsang minat belajar anak karena ditampilkan dalam bentuk animasi yang menarik dan mudah dipahami. Media ini cukup menyenangkan sesuai dengan tahap perkembangan kognitif anak usia sekolah yang mayoritas respondennya berumur 11 tahun berada dalam tahap operasional konkrit artinya aktivitas mental yang difokuskan pada objek -objek peristiwa nyata atau konkrit [8].

Sesuai dengan pernyataan yang disampaikan oleh Sudjana \& Rivai (2003) [9] mengenai manfaat penggunaan media yaitu mampu menumbuhkan motivasi belajar karena proses pembelajaran akan lebih menarik jika menggunakan media, penyampaian pesan melalui media akan lebih menarik jika menggunakan media, penyampaian pesan melalui media akan lebih dipahami sehingga tujuan pembelajaran yang diinginkan dapat dicapai dan proses belajar menjadi tidak membosankan untuk siswa. Hal tersebut menunjukkan jika media memiliki peranan penting dalam proses belajar mengajar

\section{SIMPULAN}

Dari hasil kuesioner dapat ditarik kesimpulan bahwa sebagian besar siswa sekolah dasar memiliki tingkat pemahaman yang baik tentang perawatan luka ringan sehari-hari. Namun demikian diharapkan siswa sekolah dasar paham tentang perawatan luka ringan dapat agar terhindar dari infeksi.

Edukasi, pendampingan, dan pelatihan kader kesehatan disekolah terkait perawatan luka ringan sehari-hari perlu terus dilakukan secara intensif dalam rangka mencapai derajat kesehatan anak usia sekolah dan memperbaiki kebiasaan masyarakat yang salah. 


\section{PENUTUP}

Terima kasih disampaikan kepada Ketua, WAKET III, Kepala Lembaga Penelitian dan Pengabdian Kepada Masyarakat, dan Badan Eksekutif Mahasiswa Sekolah Tinggi Ilmu Kesehatan Notokusumo Yogyakarta, serta Kepala Sekolah, guru, dan seluruh karyawan SD N Terban, Pandak, Bantul atas dukungan dan kerjasama bagi terlaksananya kegiatan pengabdian masyarakat ini.

\section{DAFTAR PUSTAKA}

National Center for Health Statistics (2010) National Health Interview Survey 2009 Data Release. (Accessed 20 December 2014). [Internet] Available at: http://www.cdc.gov/nchs/nhis/nhis 2009 data release.htm.

Vincenten JA, Sector MJ, Rogmans W, Bouter L. Parents' perceptions, attitudes and behaviours towards child safety: a study in 14 European countries. Int J Inj Contr Saf Promot. 2005;12:183-9. [PubMed] [Google Scholar]

Dirgantara, Candra Ria et al. Kartu Dokter Kecil Keluarga Indonesia (Dokkelin) Sebagai Media Permainan Edukatif Untuk Anak Usia Sekolah Dasar. J Ilm Mhs. 2013;3 No.1(1):7-10.

Riskesdas. RISET KESEHATAN DASAR. Ris Kesehat Dasar 2013. 2013;

Chang SSM, Symons RCA, Ozanne-smith J. Child road traf fi c injury mortality in Victoria , Australia ( 0 - 14 years ), the need for targeted action. Injury. 2018;49(3):604-12

Green L, Kreuter M. Health Promotion Planning. An Educational and Environmental Approach. Mountain View: Mayfield Publishing Co.; 1991.

Notoatmodjo, Soekidjo. 2010. Promosi Kesehatan Teori \& Aplikasi.Jakarta : Rineka Cipta

Siwi, L. ., Yunitasari, E, \& Krisnana, I. 2014. Meningkatkan Perilaku Konsumsi Jajanan Sehat Pada Anak Sekolah Melalui Media Audiovisual, Jurnal Gizi Masyarakat, $3(1)$

Sudjana dan Ahmad Rivai (2001). Teori Sikap Manusia \& Pengukurannya. Yogyakarta : Pustaka Pelajar 